\title{
El retroceso glaciar en la alta montaña de los Andes Peruanos. Caso: Santuario Nacional de Ampay, Apurímac
}

\author{
Glacier retreat in the mountains of the Peruvian Andes Case: National Sanctuary of \\ Ampay, Apurimac
}

\author{
Jesús Lizarzaburu ${ }^{1}$ Liselotte Diehl ${ }^{2}$ Jaime Deza $^{3}$
}

http://dx.doi.org/10.21503/CienciayDesarrollo.2013.v16i1.01

\section{RESUMEN}

El cambio climático de origen antrópico está originando un acelerado retroceso glaciar en las cumbres del Ampay.

El presente estudio es un primer intento de establecer el volumen de masa de hielo perdido por el retroceso glaciar, en el Santuario Nacional de Ampay ubicado en el distrito de Tamburco, provincia de Abancay y región de Apurímac - Perú. El trabajo se realizó los años 2009-2011, mediante estudios de reconocimiento de campo.

También se identifica la flora maderable relacionada directamente con la reserva del acuífero y se plantean alternativas para aminorar la pérdida de agua almacenándola en el colchón hídrico, gracias a la acción de coníferas y otras familias maderables, como alternativa frente al riesgo para la población de Abancay.

Palabra clave: Colchón hidrico. Superficie glaciar. Acuifero. Sumidero de anhidrido carbónico. Eutrofización

\section{ABSTRACT}

The anthropic climate change is causing an accelerated glacier retreat on Ampay summits.

This study is a first attempt to establish the ice mass volume lost by the glacial retreat on Ampay National Sanctuary located in Tamburco District, Abancay Province and Apurimac Region - Peru. The work was done in the years 2009-2011, by field reconnaissance studies.

Timber-yielding plants is identified directly with the aquifer reserves and propose alternatives to reduce the water loss storing in the edaphic system, thanks to the families of conifers and other timber, as an alternative to risk for Abancay population.

Keywords: Edaphic system, glacier surface, aquifer, carbon dioxide sink, eutrophication

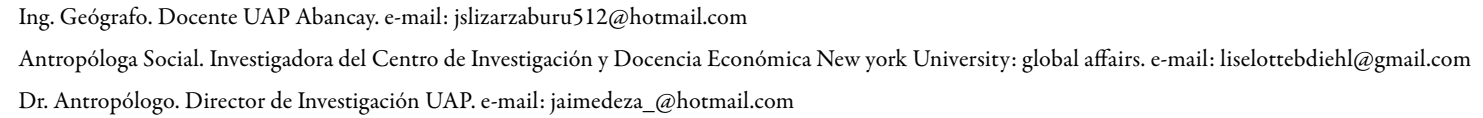




\section{INTRODUCCIÓN}

La ciudad de Abancay sufre actualmente un déficit de aprovisionamiento de agua de un millón de metros cúbicos al año (EMUSAP Abancay: 2004), lo que sugiere tomar medidas urgentes y de largo plazo para solucionar estos problemas, y prevenir problemas futuros, mediante acciones de adecuación al cambio climático actual.

El Santuario Nacional del Ampay es una de las fuentes de abastecimiento de agua de un amplio sector agrícola y ganadero del distrito, y es también la futura despensa de agua de la zona urbana en situaciones de contingencia.

El Ampay es el apu o cerro tutelar de la ciudad de Abancay, capital del departamento de Apurímac, Perú. Administrativamente pertenece al distrito de Tamburco el cual limita con el distrito de Abancay. Se encuentra entre los glaciares que se ubican por debajo de los $5400 \mathrm{~m}$. de altura, cuyas pérdidas van del $80 \%$ al $100 \%$ de sus reservas congeladas de agua dulce y de biodiversidad con grandes cambios ambientales.

Posee una altitud de 5235 m.s.n.m. y las coordenadas de su ubicación son: $13^{\circ} 33^{\prime} 13^{\prime \prime}$ latitud sur y 72०51'47" longitud oeste. El Ampay da origen al santuario nacional del mismo nombre, el cual se sitúa al noreste de la ciudad de Abancay (en automóvil se llega en 15 minutos desde la plaza de armas de la ciudad al centro de información del santuario) y cubre un área de 3636,50 Has. Fue declarado en el año 1987 como tal, por Decreto Supremo No 042-87-AG, con el objetivo de proteger la "Intimpa" (Podocarpus Glomeratus), especie forestal endémica, único género de conífera sudamericana. Es necesario indicar que este santuario también constituye una reserva del acuífero y un sumidero de anhídrido carbónico. El Ampay es un macizo rocoso en el que predomi-

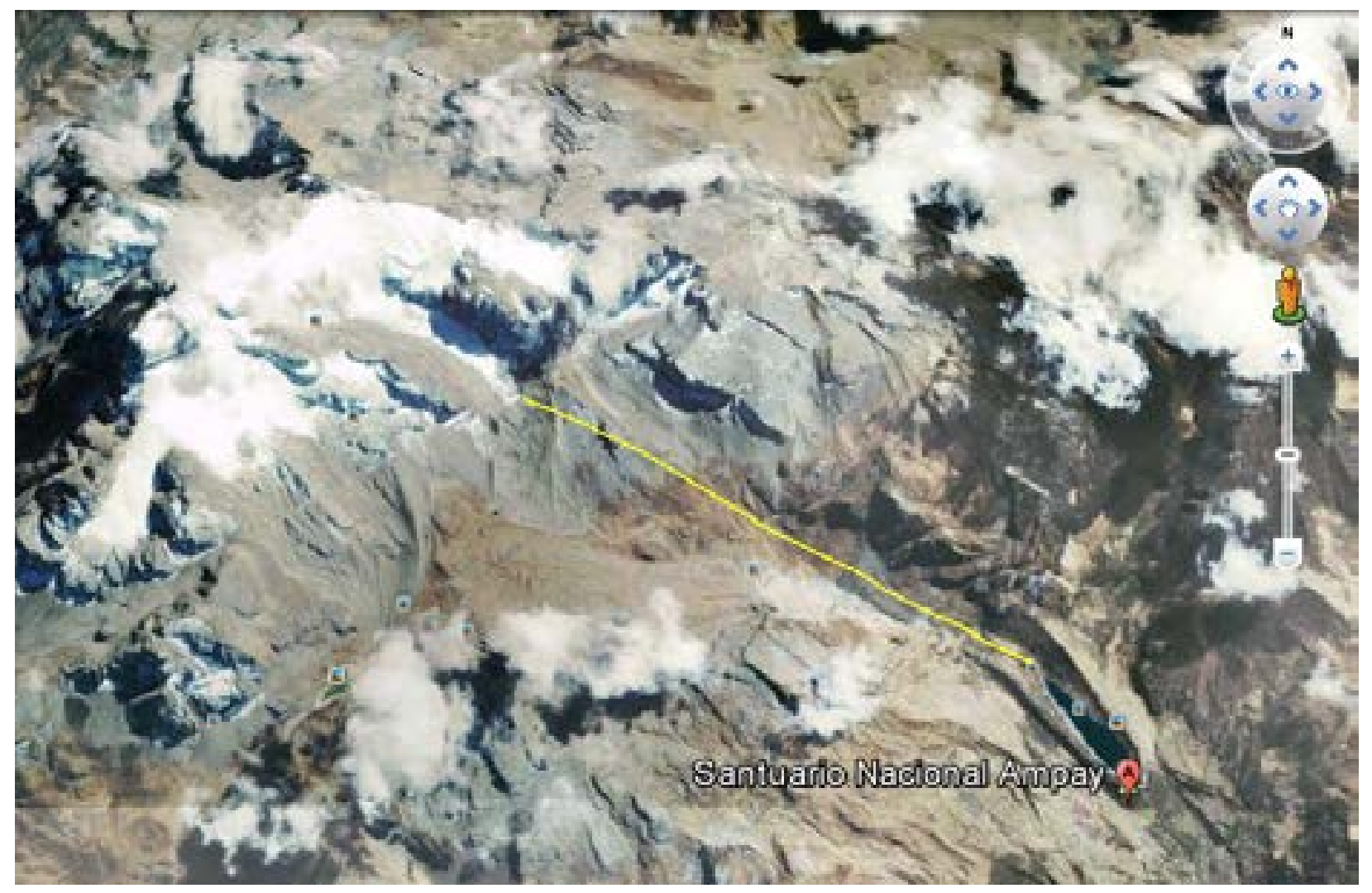

Figura 1. Imagen satelital del nevado Ampay. La línea indica el retroceso del nevado desde el año 1997. Actualmente el área se muestra como zonas rocosas totalmente desnudas 


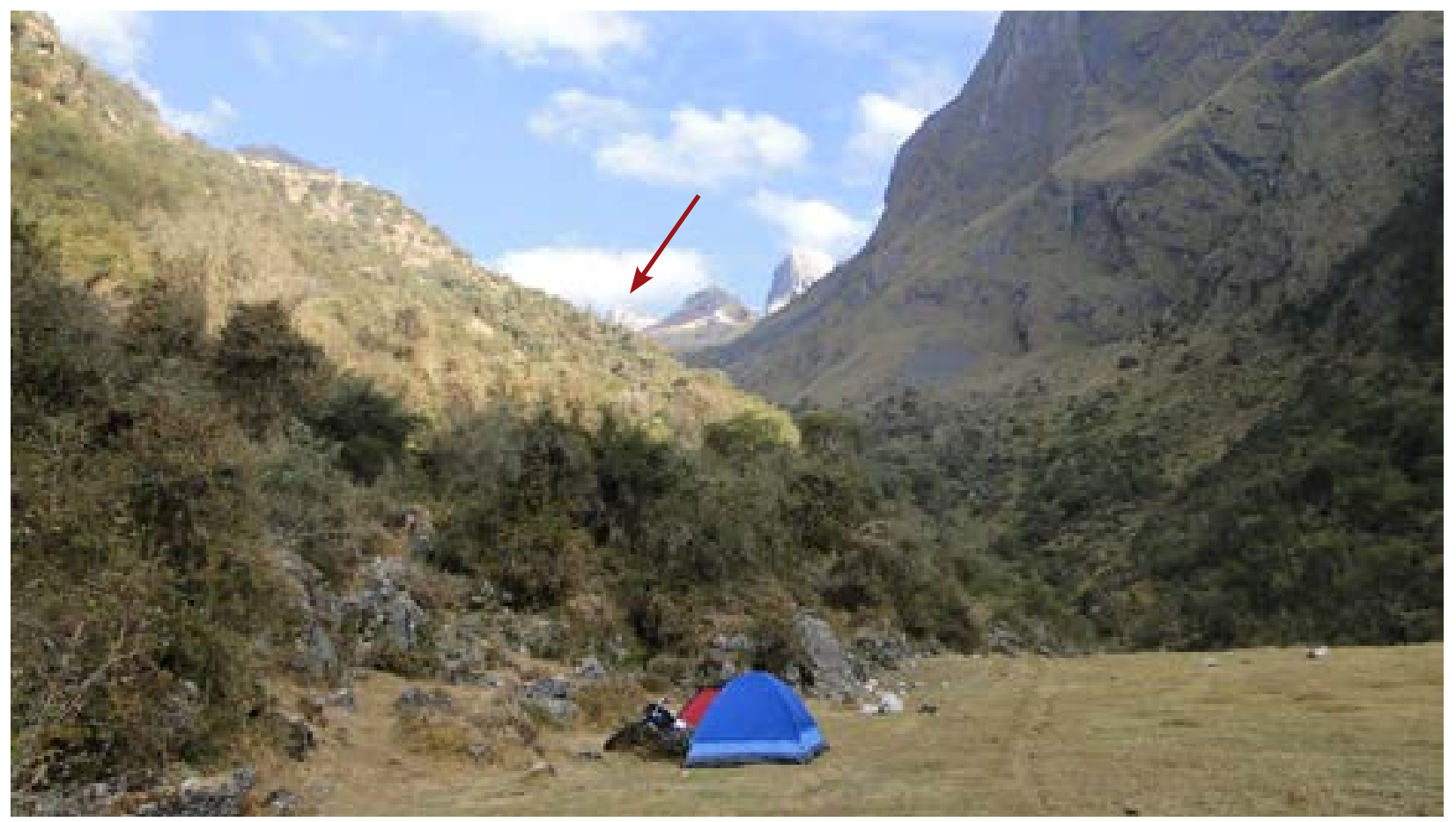

Figura 2. Campamento hasta donde en el año 1997 se extendía la superficie glaciar. Al fondo el Ampay

nan rocas sedimentarias de origen marino, cuyo origen geológico se inició en la era Cenozoica, aproximadamente hace más de 65 millones de años, remontándose a los inicios de la formación de la cordillera de los Andes. Las unidades litoestatigráficas más representativas en esta zona asociadas a la cordillera de Vilcabamba son:

- El grupo Copacabana formado por rocas sedimentarias predominantemente areniscas y calizas grises.

- El grupo Mitú formado por lodolitas y lutitas rojizas producto de depósitos continentales.

Los suelos de este lugar se ubican dentro de la clasificación de tierras de protección con una vocación de uso como bosque de protección, debido a la fuerte pendiente que domina su paisaje y a la poca profundidad de su suelo. Hasta los 3 500 m.s.n.m. predominan los suelos podsólicos y litosólicos y por encima de esta altitud predo- minan los suelos andosoles y litosoles eútricos. El suelo turboso que sostienen los bosques de intimpa, retiene hasta en un 60\% el agua que cae por precipitación, constituyendo los bosques verdaderos almacenes de recurso hídrico.

El glaciar Ampay es otra fuente de abastecimiento de agua el cual se acumula en diversas lagunas que forman parte de la cuenca del río Pachachaca:

Laguna Isucqocha

: Noroeste.

Laguna Qano

: Norte.

Laguna Yanaqocha

: Oeste.

Laguna Uspaq'ocha y Ankasq'ocha : Suroeste. Laguna Tornoqocha y Huillcaqocha : Sur.

Algunas de las lagunas como Ankasq'ocha (Laguna Chica) y Uspaq'ocha (Laguna Grande) se encuentran en proceso de eutrofización, por lo que su función como reservorio de agua presenta el peligro de fenecer. 
La Laguna Chica (“Ankasq'ocha”, palabra quechua que puede interpretarse como "Laguna de los flancos o bandas" o la que antecede), se encuentra ubicada dentro de una depresión de origen glacio fluvial, el lecho de esta laguna presenta sedimentos arcillosos con notoria cantidad de materia orgánica asociado a depósitos morrénicos calcáreos, presentando bordes oblicuos entre sí.

La Laguna Chica, ubicada a 3200 metros de altitud, posee una superficie de $3200 \mathrm{~m}^{2}$, alcanza un volumen máximo de hasta $125000 \mathrm{~m}^{3}$ de agua, durante los meses de enero a abril. Posteriormente durante los meses de junio a noviembre, periodo de estío, la laguna baja su nivel por debajo de los $20000 \mathrm{~m}^{3}$ de agua.

El material rocoso sedimentario de su base, permite infiltraciones que dan origen a ríos kársticos y a la presencia de puquiales en la parte inferior de la vertiente.

La evaporación es otro de los fenómenos que reduce el volumen de agua acumulada. Su ubicación en pleno bosque de "intimpas" genera un ecosistema meso térmico de bosque heterogéneo.

La Laguna Grande (“Uspaq’ocha”, nombre quechua proveniente de los vocablos uspa, ceniza, y q'ocha, laguna) que podría entenderse como laguna gris, cuyo nombre debe estar relacionado a la particularidad de adoptar la coloración del cielo comúnmente cargado de nubes la mayor parte del año.

Está ubicada a 400 metros de distancia de Laguna Chica, en dirección noreste y a 3750 m.s.n.m. Posee una superficie de $67500 \mathrm{~m}^{2}$. En épocas de lluvias logra una capacidad de almacenamiento de hasta $540000 \mathrm{~m}^{3}$ de agua, descendiendo en el periodo de estiaje por debajo de los $60000 \mathrm{~m}^{3}$ de agua.
La laguna es alimentada todo el año con los deshielos del nevado Ampay y de las precipitaciones estacionales. Los deshielos forman un río subterráneo que emerge muy cerca de la laguna. Las aguas de la laguna adquieren diferentes tonalidades desde verde a azul añil, por la presencia de algas y plancton en el fondo de la misma y debido al reflejo del cielo.

Los procesos erosivos sobre las rocas calizas y su disposición tecto dinámica en la alta montaña no sólo han permitido el desarrollo de ríos subterráneos o kársticos, sino también el modelado de las diversas lagunas que se ubican por encima de los $4000 \mathrm{~m}$ de altitud.

\section{Objetivos}

Los objetivos principales de esta investigación se orientan a identificar el proceso de desglaciación que está ocurriendo en las cumbres del nevado Ampay, a consecuencia del cambio climático, y a identificar las principales familias de flora maderable relacionada directamente con la reserva del acuífero y sumidero de anhidrido carbónico.

\section{MATERIALES Y MÉTODOS}

Para la realización del presente trabajo se procedió a trabajar en tres etapas que a continuación se especifican.

\section{Primera Etapa:}

\section{Recopilación de información y elaboración del Mapa Base.}

La recopilación de la información se realizó por áreas temáticas, como se indican:

Historia: Archivo Regional del Cusco, Biblioteca Municipal de Abancay.

Geología: INGEMMET

Geomorfología: INGEMET, INRENA

Edafología: INRENA, Ministerio de Agricultura. 


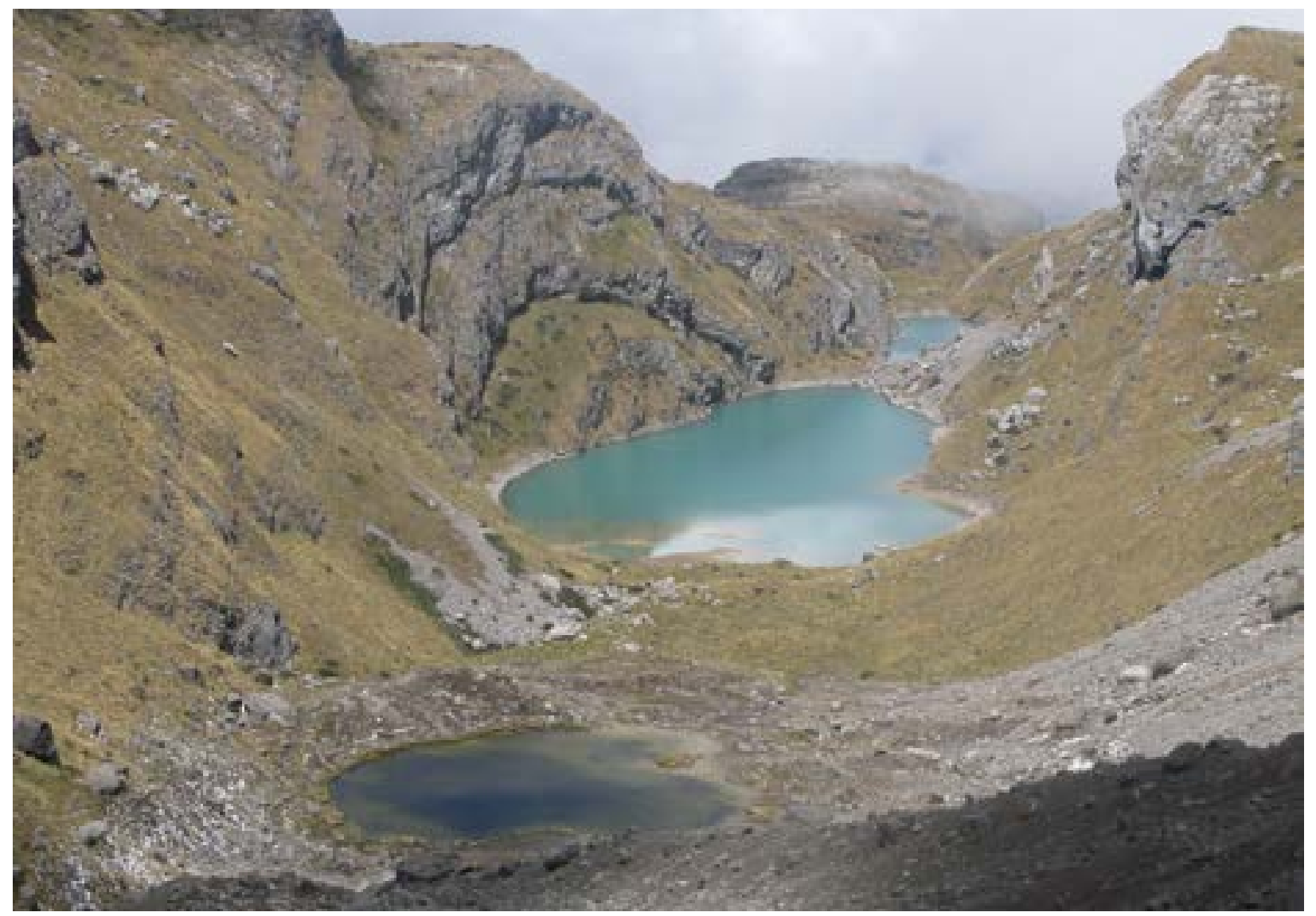

Figura 3. Lagunas ubicadas por encima de los 4000 metros de altitud, modeladas sobre rocas sedimentarias, como producto del retroceso glaciar

Meteorología: SENAMHI, IDMA

Climatología: SENAMHI, INRENA

Botánica: INRENA, IDMA

Zoología: INRENA, IDMA

Ecología: INRENA

Riesgos: INDECI

El mapa base se elaboró considerando la información cartográfica del Área Natural Protegida, Santuario Nacional de Ampay.

En esta etapa se planificó el trabajo de campo. Se establecieron los equipos de trabajo y se definió los procedimientos para el gabinete y de campo.

La información de imágenes satelitales fue recopilada de diversas fuentes, desde el año 1997 al 2011. Trabajándose la misma con software, como el ERDAS y ARCGIS.

\section{Segunda Etapa:}

Reconocimiento de campo e instalación de estaciones.

El trabajo en la zona de interés se realizó como estudios de reconocimiento de campo. El ingreso a la zona del glaciar se hizo por tres rutas:

Camino Karkatera

Camino Laguna Chica

Camino Querapata

Los estudios de reconocimiento se realizaron cada 15 días entre los meses de Mayo a Julio y de Septiembre a Noviembre, en los años 2009 y 2011.

La información recopilada estuvo referida a las áreas temáticas indicadas en la primera etapa del presente estudio, poniendo énfasis en el modelado glaciar presente en esta montaña. 


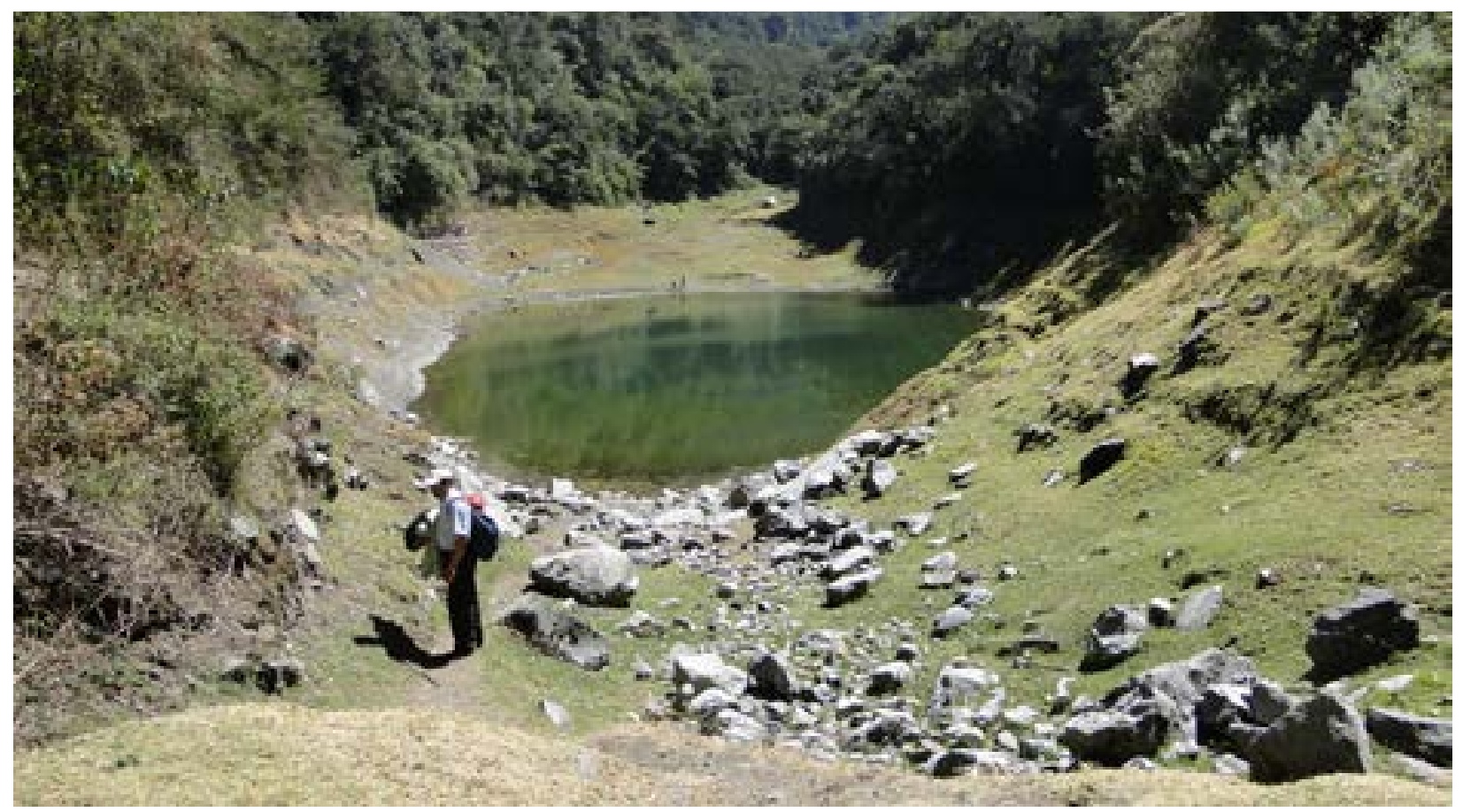

Figura 4: Laguna de "Ankasq'ocha" (3 200 m.s.n.m.), se encuentra en proceso de eutroficación en suelos con horizontes edáficos de escaso desarrollo y dominados por una fuerte pendiente, se clasifican como tierras de protección, deben destinarse al uso como bosques de protección

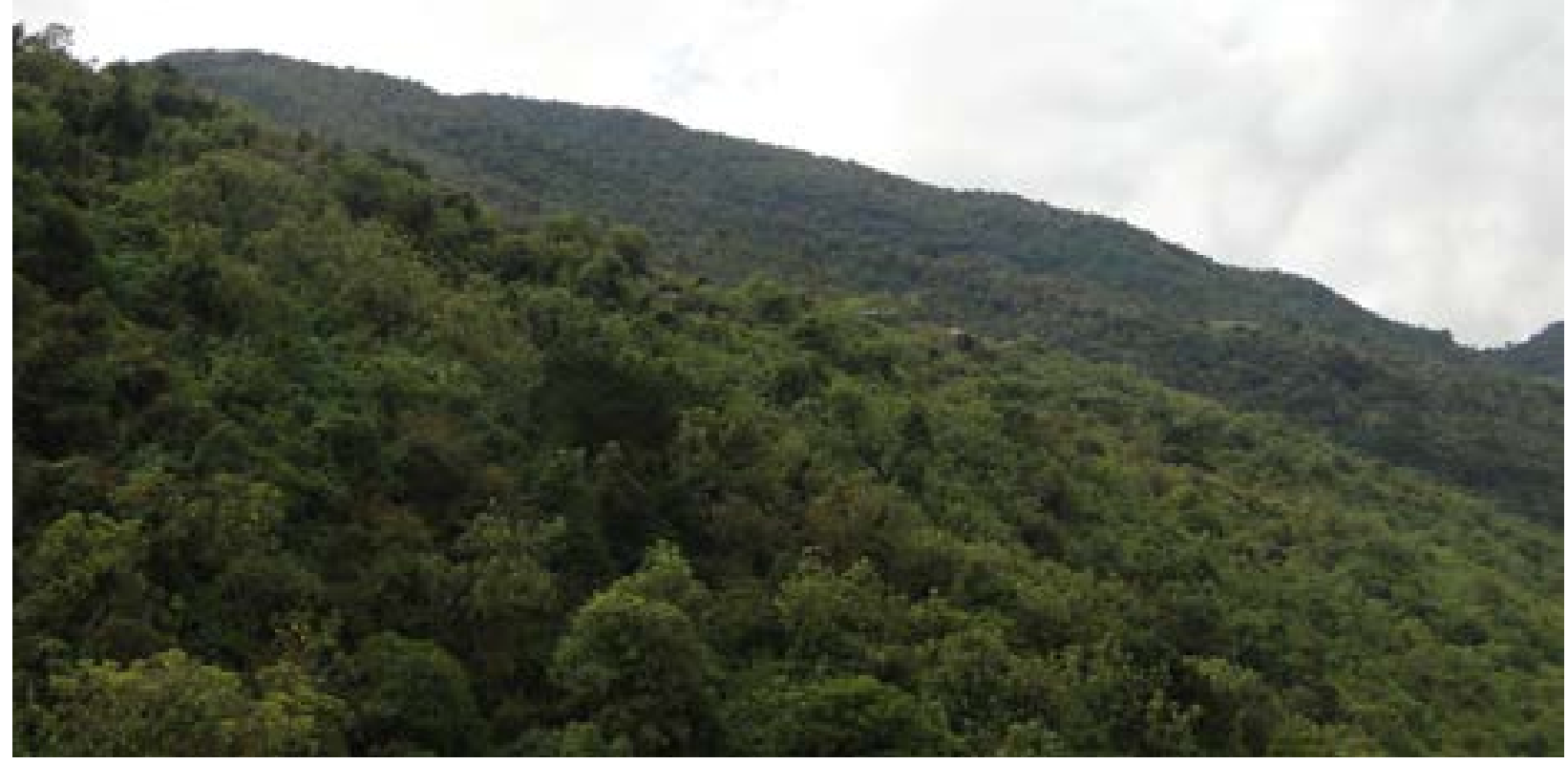

Figura 5. El bosque no solo cumple la función de ser sumidero de anhídrido carbónico, es también un almacén del recurso hídrico. El 60\% de las lluvias quedan retenidas en estas zonas 
Mediante el uso de la carta nacional, de una imagen satelital y con el apoyo de un gps navegador, se fijaron los lugares hasta donde llegó el hielo, en base a las huellas dejadas por el mismo. Esta información se contrastó con las imágenes satelitales, trabajo que se realizó en gabinete. También se realizaron entrevistas con pobladores que habitan en la zona de estudio.

\section{Tercera Etapa:}

\section{Elaboración del Informe y redacción final.}

En esta etapa se organizó la información recopilada para su presentación. Se recurrió a solicitar el apoyo de especialistas externos en Sistemas de Información Geográfica: Ing. Geógrafo Carlos Sánchez Acostupa (UNAMBA), Biólogo. Carlos Coacalla Castillo (UNAMBA), Ing. Agrónomo Yogna Dueñas Guevara (Gobierno Regional de Apurímac) y Bach. Ing. Geográfico Luis Gonzales Ferro (Gobierno Regional de Apurímac).

El estudio, en su primera etapa, se basó en los informes satelitales Landsat.

La exploración de superficie se realizó en compañía de pobladores residentes en el lugar, conocedores y testigos, como informantes de las márgenes de la superficie del glaciar en su retroceso desde el año 1997 hasta la actualidad; es así como se marcaron los extremos de los límites de la actual superficie glaciar del Ampay.

\section{RESULTADOS}

Este trabajo debe ser considerado como un estudio de carácter exploratorio, ya que no existen antecedentes específicos del mismo.

El retroceso glaciar en el Ampay, estudiado desde el año 1997 hasta el año 2011, registra 3 kilome- tros de superficie de hielo en las faldas Su Oeste, una pérdida estimada de 160 hectáreas de superficie de hielo, lo que significa la reducción de la disponibilidad residual de un promedio de 4800 000 metros cúbicos de masa sólida (los cálculos se realizaron haciendo uso de imágenes satélites Landsat e informes personales que nos proveían los pobladores con quienes recorrimos el área). Las consecuencias de la reducción de los glaciares en una zona andina como ésta, con un periodo estacional prolongado de escasa precipitación, resultan de alto riesgo para las poblaciones locales aguas abajo y sus actividades económicas.

El Ampay visto desde el aire tiene la forma de un macizo fuertemente escarpado, debido al plegamiento morfo estructural que ha sufrido todo el conjunto rocoso. Las pendientes promedio fluctúan entre $28 \%$ y $32 \%$ alcanzando máximas de $36 \%$ a $45 \%$ y en las zonas de planicies éstas no superan el $8 \%$.

La acción glaciar y periglaciar es notoria hasta los 3500 m.s.n.m. Es posible observar formas aborregadas como en la periferia de la Laguna Grande, también depósitos de morrenas y tilitas. En forma dispersa se puede observar el material gelifractado de dimensiones muy variadas.

En la zona por debajo de los 3500 metros los materiales transportados han perdido sus aristas y pueden observarse vestigios de la última glaciación que bajó hasta los 2500 metros de altitud.

La excesiva pérdida de la cobertura vegetal y el aumento del índice de liquidez del suelo han dado origen a fenómenos aluviales con efectos devastadores, como los sucedidos en el mes de febrero del año 1997 que afectaron a las comunidades que se ubican en sus faldas al Sur Este del Santuario. 
Especies forestales del Santuario Nacional de Ampay

Los bosques de intimpa (Podocarpus glomeratus) viven asociados a numerosas especies de flora y fauna, aquí podemos observar especies vegetales de tipo forestal (Tabla 1)

\section{Fauna del Santuario Nacional de Ampay}

La fauna podemos dividirla en mamíferos, roedores y aves.

Entre los mamíferos distinguimos: el "puma" (Puma concolor), el "zorro andino" (Pseudalopex culpaeus), el "venado" o "luichu" (Odocoileus virginianus), "taruca" (Hippocamelus antisensis). Entre los roedores tenemos el "cuy silvestre" o "poronqoe" (Cavia tschudii) y la "vizcacha" o "wisq'acha" (Lagidium Lagidium viscacia). En cuanto a las aves podemos mencionar a la " $A p u$ rimac spinetail' (Synallaxis courseni) ave endémica, "perdiz de Taczanowski" (Nothoprocta taczanowskii) especie en peligro crítico, "verde y blanco de Hummingbird" (Amazilia viricauda), "garganta de fuego" (Metallura eupogon), "carpintero andino" (Colaptes rupicola), "ceja blanca" (Conirostrum ferrugineiventre), "tororoi de cabeza listada" "asthenes canastero" (Asthenes ottonis), "gavilán dorsigris" (Leucoptermis occidentales), "gaviota andina” (Larus serranus) entre las principales y más numerosas.

Tabla 1. Flora maderable del Santuario de Ampay

\begin{tabular}{|l|l|c|}
\hline \multicolumn{1}{|c|}{ NOMBRE COMÚN } & \multicolumn{1}{c|}{ NOMBRE CIENTÍFICO } & FAMILIA \\
\hline Intimpa & Podocarpus glomeratus & Podocarpus \\
\hline Chachacomo & Escallonia resinosa & Grossulanaea \\
\hline T'asta & Escallonia myrtilloides & Grossulanaea \\
\hline P'fanca $^{\prime}$ & Escallonia heverea & Grossulanaea \\
\hline Atoc cedro & Cedrela lilloi & Meliaceae \\
\hline Nogal & Inglans neotropica & Inglandeceae \\
\hline Calasto & Smallanthus glabratus & Asteraceae \\
\hline Clasto & Smallanthusparviceps & Asteraceae \\
\hline Lima lima & Primus rigida & Rosaceae \\
\hline Maju manzana & Hesperomeles lanuzinosa & Rosaceae \\
\hline Huaman Quero & Styloceras launfolia & Buxaceae \\
\hline Chuyllur & Vallea stipularis & Elafocarpaceae \\
\hline Chuyllur & Citharexyliun launfolium & Verisenaceae \\
\hline Chuyllur & Cornusperuvianus & Cornaceae \\
\hline Unca & Myrcianthus oreophylla & Myrtaceae \\
\hline Huankar tipa & Randia boliviana & Rubiaceae \\
\hline Koto Kiswar & Gynoxys spp & Asteraceae \\
\hline Sacha Kera & Lupinus ampaiensis & Fabaceae \\
\hline Llutha - lluthu & Myrsine spp & Myrsinaceae \\
\hline Ollantay & Saracha punctata & Solanaceae \\
\hline Molle & Shinus molle & Anacardiaceae \\
\hline Lambras & Alnus jorullensis & Betulaceae \\
\hline Queñua & polylepis & Rosaceae \\
\hline Wankartipa & Randia boliviana & Rubiaceae \\
\hline
\end{tabular}

Fuente: Elaboración propia 


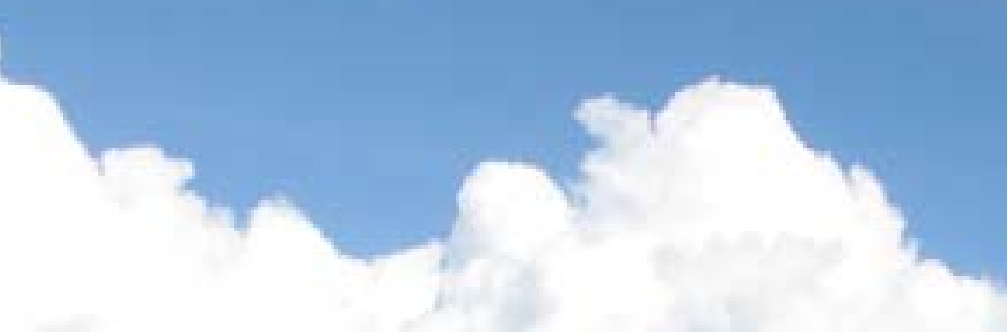




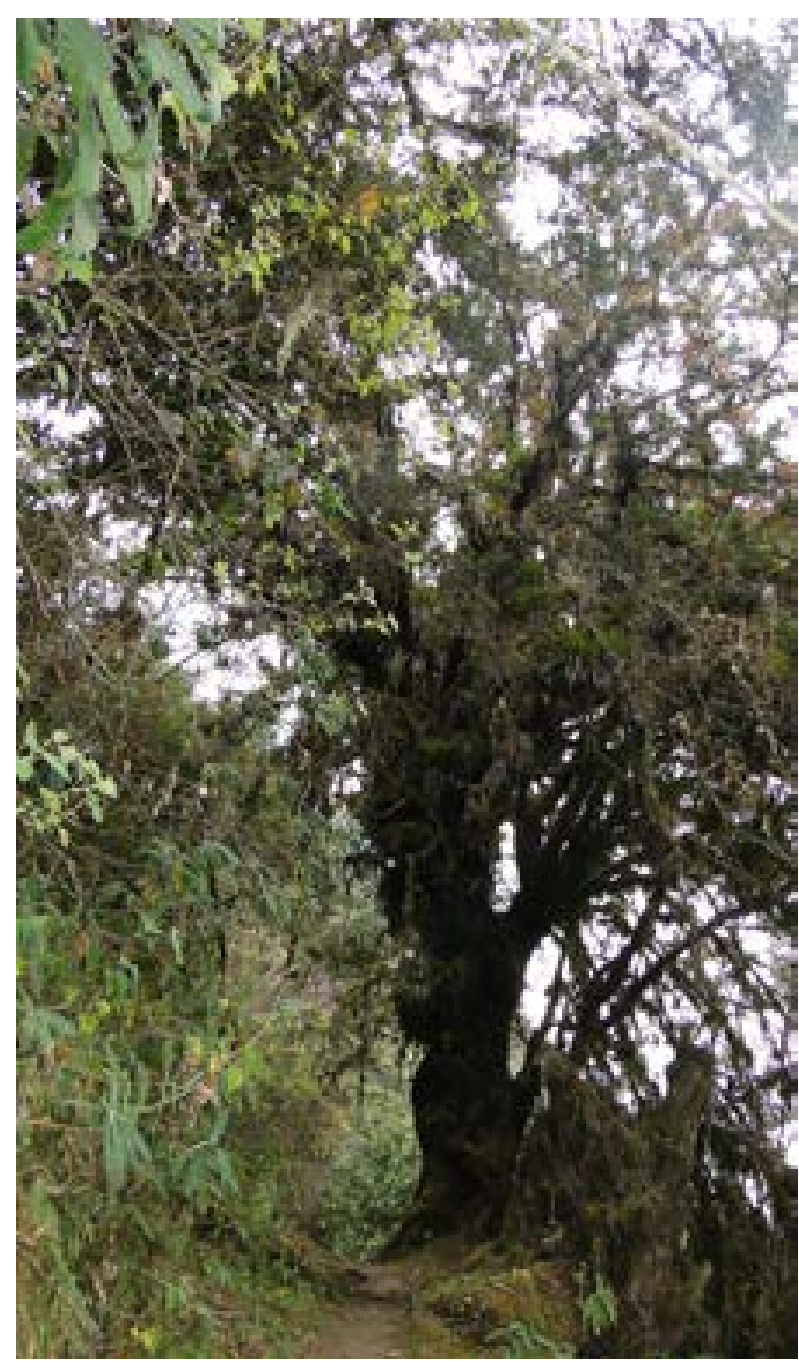

Figura 7. Intimpa (Podocarpus glomeratus) silvestre

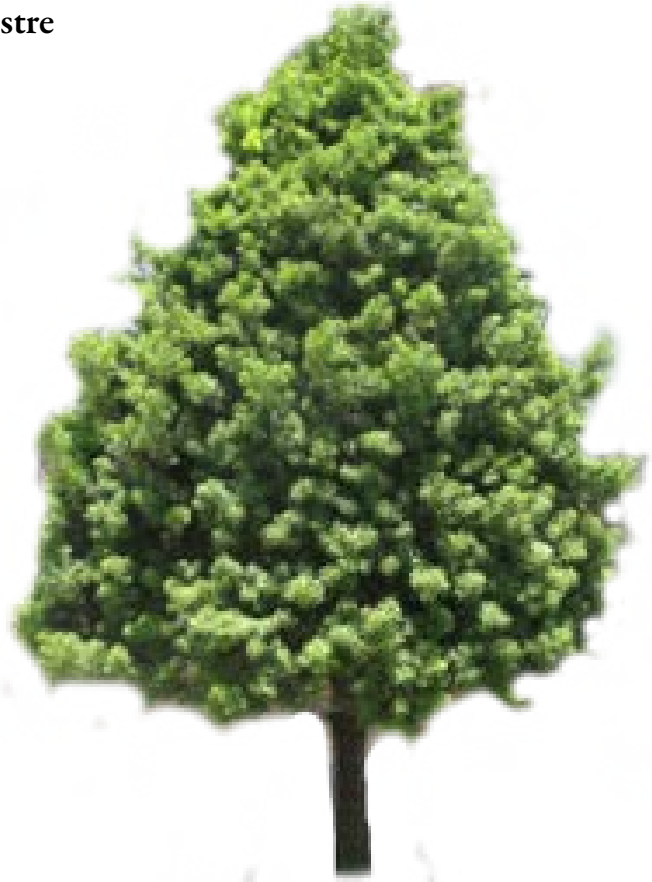

Figura 8. Intimpa (Podocarpus glomeratus) cultivada
No existen estudios hidrogeológicos, por lo tanto, es imposible determinar la reserva del acuífero subterráneo, pese a que existen numerosos manantes o puquiales de origen kárstico.

\section{DISCUSIÓN}

Combinar el trabajo de campo con la información satelital, aplicando el método de Elevación, permitió obtener una primera aproximación al problema estudiado. Los rasgos de erosión dejado por el hielo sobre la roca sedimentaria constituyen un indicador de gran valor para el presente estudio, pero no se invalida otras técnicas con fines comparativos o de lograr mayor precisión.

Los glaciares, las lagunas y los bosques, son almacenes de agua en el área natural protegida Santuario Nacional de Ampay; pero el retroceso glaciar, la eutroficación de las lagunas, la deforestación y quema de los bosques, la ganadería y el turismo de aventura, son los problemas que se presentan en esta área natural protegida y que debemos de enfrentar.

La importancia de conservar los glaciares, las lagunas y los bosques de alta montaña, se debe a que éstos constituyen la fuente de abastecimiento de agua de las zonas urbanas y rurales, y los productores de oxigeno para la humanidad. Las ciudades andinas en el Perú que atraviesan por problemas de abastecimiento de agua similares son Chachapoyas, Huaraz, Huancavelica, entre otras.

Las actividades que actualmente están originando el deterioro del área a nivel local son la ganadería de tipo extensiva, la agricultura de secano y el turismo de aventura. La ganadería está incrementando la velocidad de los procesos de eutroficación de las lagunas Grande y Chica. La agricultura acelera los procesos erosivos y el peligro de deslizamientos y aluviones. El turismo está incrementando la deforestación y la contaminación de los medios lénticos y el suelo de la misma. A ello agreguemos 
la quema del bosque derivada de las malas prácticas agrícolas y del turismo irresponsable.

La Universidad Alas Peruanas, ha identificado estos problemas y plantea la necesidad de reforestar la cabecera de la cuenca con especies análogas, como la intimpa (Podocarpus glomeratus), queñual (Polylepis sp), y el chachacomo (Escallonia resinosa), entre otras especies. Detener el proceso de eutroficación de las lagunas, mediante la reorientación de las actividades económicas dentro del área natural protegida. Realizar el monitoreo de los principales parámetros físico naturales y económicos sociales que tiene una influencia en el mantenimiento de este ecosistema. El aumento de la cobertura vegetal en las cabeceras de cuenca mediante la reforestación análoga es una de las acciones inmediatas en estas zonas, así como el manejo y administración adecuada de las actividades económicas que se realizan en la alta montaña.

\section{CONCLUSIONES}

En los últimos años (1997 - 2011) ha retrocedido la superficie glaciar del Ampay 160 hectáreas, dejando a la vista sus morrenas "frescas". No podemos determinar el volumen perdido por falta de información al respecto.

La actual distancia del glaciar ha contribuido a que tres lagunas que forman parte de la cadena del deshielo se hayan secado y las que aún son reservorios, han disminuido su volumen hasta en un $50 \%$ con relación al volumen de 1997 .

La desglaciación acelerada del Ampay constituye una amenaza para la población, como recurso hídrico de reserva para la ciudad.

\section{RECOMENDACIONES}

Uno de los proyectos alternativos que permitiría mitigar los efectos sociales de la desglaciación sería el proyecto de reforestación análoga o con

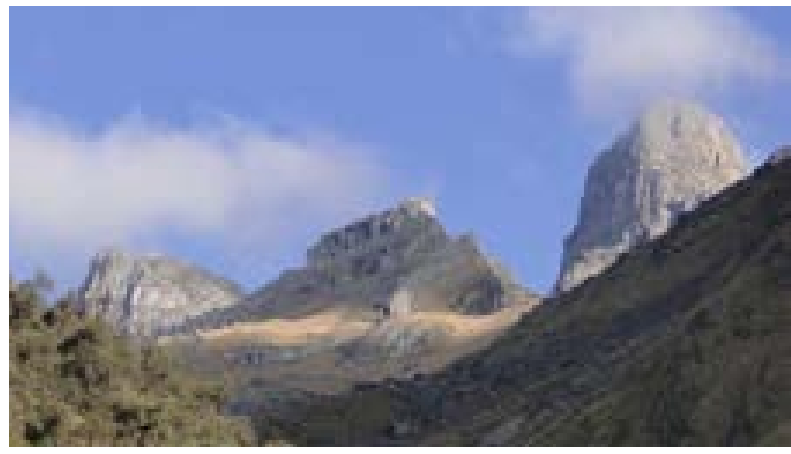

Figura 9. Cumbres que estuvieron cubiertas de nieve

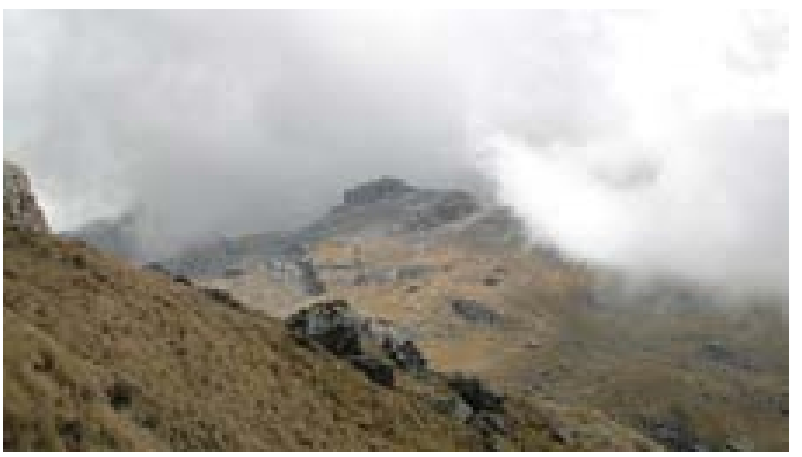

Figura 10. Retroceso de la superficie glacial, obsérvese la morrenas

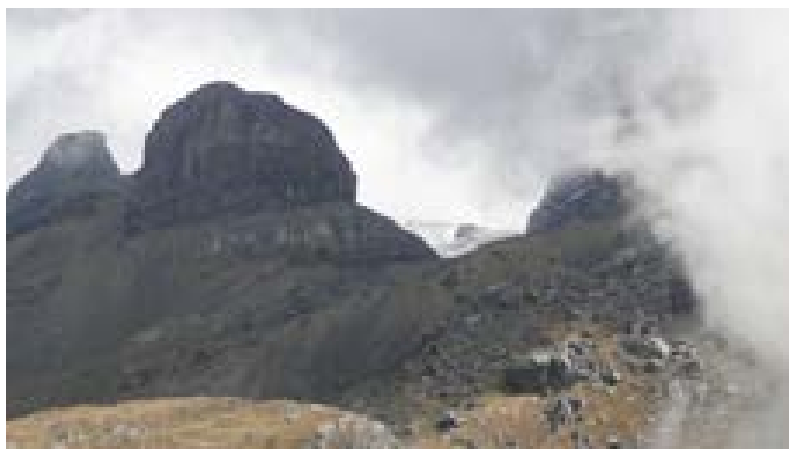

Figura 11. Al fondo las orillas actuales del nevado Ampay

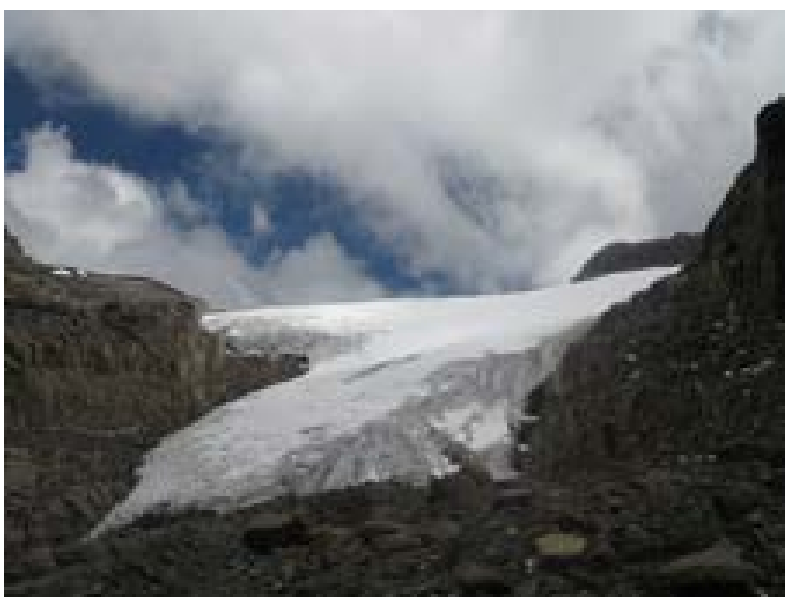

Figura 12. Orillas del Ampay actual 
especies tipicas del lugar, considerando los pisos altitudinales a los que pertenecen, lo que permitiría una flora nativa en cada piso. Es asi como llegamos a considerar la siguiente propuesta como una alternativa viable para la zona:

Se debe iniciar en la cabecera de cuenca, a partir de los bosques relictos existentes, con especies como el queñoal (Polylepis sp.) entre los 4600 y 4000 $\mathrm{m}$. de altitud. En el piso ubicado entre los 4000 y los $3600 \mathrm{~m}$. tenemos el chachacomo (Escallonia $s p$.) como especie más representativa. Con intimpa (Podocarpus glomeratus) se reforestaría el piso ubicado entre los 3800 y $3100 \mathrm{~m}$. En el piso de los 3100 a los $2800 \mathrm{~m}$ se puede ubicar el aliso (Alnussp.)

¿Este bosque con una turba reimplantada funcionaría como una esponja que retiene el $60 \%$ de las precipitaciones?, permitiendo la continuidad de los ciclos naturales, evitando la extrema disminución de agua en la cuenca.

Un ejemplo no muy lejano de lo que podría suceder con el Ampay nos lo da el cerro Karcatera, ubicado a 4609 m.s.n.m, al Oeste de la cima del glaciar Ampay, entre las coordenadas 72。 57’05" L. O. y $03^{\circ} 33^{\prime} 11^{\prime \prime}$ L. S. Este cerro, 25 años atrás estuvo cubierto de manera permanente de hielo; así lo informaron los pobladores del lugar, y vemos que la cima aún conserva los rasgos de un modelado glaciar. En las épocas de heladas y de verano meridional se encuentra cubierto de una delgada capa de nieve y granizo, la cual se derrite rápidamente durante el día. La comunidad campesina de Karcatera actualmente demanda la construcción de un reservorio para mantener la continuidad de la actividad agrícola en esta zona, y el apoyo de diversas instituciones para la ampliación y conservación de sus bosques.

\section{BIBLIOGRAFÍA}

1. Bird life International. Santuario Nacional del Ampay. World Congress, Otawa, Canada 2012.
2. Wild World life. Diagnóstico y Plan Maestro del Santuario Nacional de Ampay. 1999. Lima. IDMA.

3. Instituto de Desarrollo y Medio Ambiente. 1999. Plan de Desarrollo Forestal para la Zona De Amortiguamiento del Santuario Nacional de Ampay. Abancay: IDMA.

4. Instituto Nacional de Estadística e Informática. Censos Nacionales 2007: XI de Población y VI de Vivienda, INEI.

5. Instituto Nacional de Recursos Naturales, Oficina de Evaluación e Información de Recursos Naturales. Mapa fisiográfico y capacidad de uso mayor de las tierras escala 1:250 000: memoria descriptiva. Lima: ONERN; 1988.

6. Lagos, Gladys. 1988. Inventario y Catalogación Arqueológica, de los sectores Noreste y Noroeste del Santuario Nacional del Ampay. Distritos de Abancay y Tamburco. Cusco: UNSAAC.

7. Rene Marocco. 1978. Geología de los cuadrángulos de Andahuaylas, Abancay y Cotabambas. Boletín 27, 53 páginas, INGEMMET.

8. T. W. Pyrcz, A. L. Viloria, G. Lamas \& P. Boyer. 2011. La fauna de mariposas de la subfamilia Satyrinae del macizo del Ampay (Perú): diversidad, endemismo y conservación (Lepidoptera: Nymphalidae). SHILAP Revta. lepid., 39 (154), junio.

9. Venero Gonzales, Luis. 1989. Ampay Santuario Nacional. Boletín de Lima, $\mathrm{N}^{\circ} 61$.

\section{Correspondencia}

Jesus Lizarzaburu

e-mail:jslizarzaburu@hotmail.com 